\title{
Umbilical metastasis of unknown primary presenting as umbilical hernia: a case report
}

\author{
This article was published in the following Dove Press journal: \\ Pathology and Laboratory Medicine International \\ 9 November 2010 \\ Number of times this article has been viewed
}

\author{
Ibrahim W Adamu' \\ Noubar Kevorkian' \\ Genato Romulo' \\ Stephen S Carryl' \\ Armand Asarian' \\ Philip Q Xiao² \\ 'Department of Surgery, ${ }^{2}$ Department \\ of Pathology, The Brooklyn Hospital \\ Center, Brooklyn, NY, USA
}

\begin{abstract}
Umbilical metastasis is well known to be a late stage of malignancy and is associated with a poor prognosis. The majority of such cases are associated with primary gastrointestinal and gynecologic malignancies, and fewer cases are noted to derive from the thoracic cavity and the urinary tract. In this report, we describe a rare case of metastasis that presented as incarcerated umbilical hernia with no primary sites found. Extensive work-up, including tumor markers, imaging studies, endoscopies, and immunohistochemical analysis, failed to identify the primary source of this malignancy; this was a rare case of Sister Mary Joseph's nodule with unknown primary. Therefore, it is very important for a surgeon to consider metastasis among the differential diagnosis of umbilical hernia.
\end{abstract}

Keywords: umbilical metastasis, Sister Mary Joseph's Nodule, hernia

\section{Case report}

A 77-year-old female with history of hypothyroidism, hypertension, and hypercholesterolemia, was seen initially in the office with complaints of umbilical swelling associated with mild discomfort for 1 month, but without other constitutive gastrointestinal symptoms such as pain, nausea, vomiting, early satiety, diarrhea, constipation decreased appetite, or weight loss. Diagnosed with incarcerated umbilical hernia, she presented to ambulatory surgery for elective umbilical hernia repair. The patient had no family history of malignancy. Physical exam was significant for a soft, $4 \mathrm{~cm}$ nontender umbilical bulge with irreducible contents. No other abdominal masses were found and the liver, spleen, thyroid, cervical, and supraclavicular lymph nodes were nonpalpable. Rectal exam did not reveal any palpable masses or firmness. Gynecology consultation was performed and revealed no ovarian mass. Previous supracervical hysterectomy was for uterine fibroids. Cervix was unremarkable. Basic laboratory work-up including liver function tests did not show any abnormalities.

During the operation for the proposed umbilical hernia repair, a $3 \mathrm{~cm}$ soft tissue mass attached to the omentum and herniating through an umbilical defect was found and completely resected. A few lymph nodes measuring about 1 to $2 \mathrm{~cm}$ were found attached to the mass. A frozen section of this specimen was reported as adenocarcinoma. The patient developed atrial fibrillation while in the operating room and hence the procedure was terminated with repair of the umbilical defect without further exploration. Postoperatively the patient was admitted for treatment of the atrial fibrillation and work-up for malignancy.
Correspondence: Philip Xiao

Department of Pathology,

The Brooklyn Hospital Center,

Brooklyn, NY I I 20I, USA

$\mathrm{Tel}+\mathrm{I} 7182508207$

Fax +I 7182508056

Email pqx900।@nyp.org 


\section{Image studies}

Computed tomography (CT) of the abdomen and pelvis revealed 2 small soft tissue nodules $(3.5 \mathrm{~cm}$ and $2.2 \mathrm{~cm}$, respectively) in the left iliac region, a $4.3 \times 3.6 \mathrm{~cm}$ right hepatic cyst, a $2.4 \times 1.7 \mathrm{~cm}$ left hepatic cyst, and multiple bilateral renal cysts. There was no abdominal lymph node enlargement and no gastric or intestinal masses. Bilateral adrenal nodules measuring up to $2.7 \mathrm{~cm}$ were identified and due to the patient's medical condition, biopsy could not be performed. Endoscopy revealed hiatal hernia and mild chronic gastritis. Colonoscopy was performed and revealed unremarkable but moderate to severe diverticulosis and benign polyp. A whole body positron emission tomography $/ \mathrm{CT}$ scan revealed a $4.4 \times 3.6 \mathrm{~cm}$ malignant mass within the umbilical region extending into the peritoneal space, and a second malignant soft tissue opacity measuring $2.9 \times 2.2 \mathrm{~cm}$ adjacent to the right lobe of the liver. However, due to the patient's medical condition, biopsy could not be performed. A third hypermetabolic malignant-appearing nodule adjacent to the urinary bladder measured $2.8 \times 2.4 \mathrm{~cm}$. Multiple hypermetabolic left external iliac lymph node compatible with malignancy were seen. Breast exam and mammogram were unremarkable.

\section{Pathology findings}

Grossly the specimen measured $4.2 \times 3.5 \times 3 \mathrm{~cm}$ in greatest dimension. Cut section revealed a fleshy dense tan surface. Microscopic examination revealed sheets of hypercellular malignant cells characterized by large pleomorphic nuclei with coarse chromatin or hyperchromasia, irregular nucleoli, and abundant mitotic figures. The tumor formed a vague acinar or trabecular pattern (Figure 1). Immunohistochemical study revealed that tumor cells were positive for CK7 and negative for CK20, TTF-1, CDX2, CA125, and CA19.9 (Figure 2). Serum CEA level was normal. The final pathology was reported as metastatic adenocarcinoma without a specific primary site.

\section{Discussion}

Since its initial use by Hamilton Bailey in 1949, many articles and reviews have been published about the eponym Sister Mary Joseph's Nodule, a rare clinical finding. ${ }^{1-3}$ Possible routes of metastasis to the umbilicus may include arterial, venous, and lymphatic channels; however, the direct extension of tumor through the peritoneum appears to be the most favorable pathway. ${ }^{2,46}$ Clinical history, histological studies combined with immunohistochemical stains, and tumor markers analysis usually help in identifying the primary site..$^{2,7,8}$

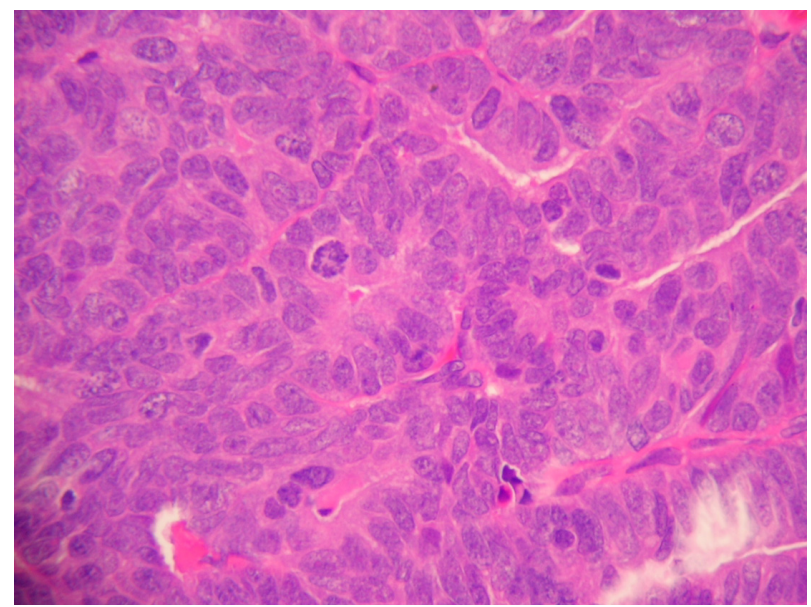

Figure I Microscopic examination (H\&E stain, 40x) of the umbilical nodule reveals sheet of highly malignant cells showing hyperchromatic pleomorphic irregular nuclei with glandular formation. Mitotic activity is easily identified.

Most tumors are noted to be adenocarcinomas followed by squamous cell carcinomas and undifferentiated tumors, ${ }^{2,5,9}$ the majority of cases deriving their primaries from gastrointestinal tract (about 50\%), gynecologic organs (about 28\%), and genitourinary and respiratory tracts. ${ }^{9}$ It was reported that the commonest origins are stomach, ovary, colon, and pancreas. ${ }^{8}$ About $15 \%$ to $30 \%$ of cases are reported to have occult primaries. ${ }^{1,4,9}$ As in our case, this may also be the only clinical manifestation of malignancy, or the recurrence or relapse of a known malignancy,,$^{2,4,5,7,10}$ and may present as a frank umbilical hernia. ${ }^{11}$

Based on the origin of most primaries, consideration for extensive work-up including CT scan of the abdomen ${ }^{12}$ and chest, and upper and lower gastrointestinal endoscopy with biopsy of suspicious lesions, and serum assay for tumor markers should be ordered in the evaluation of any mass lesions of

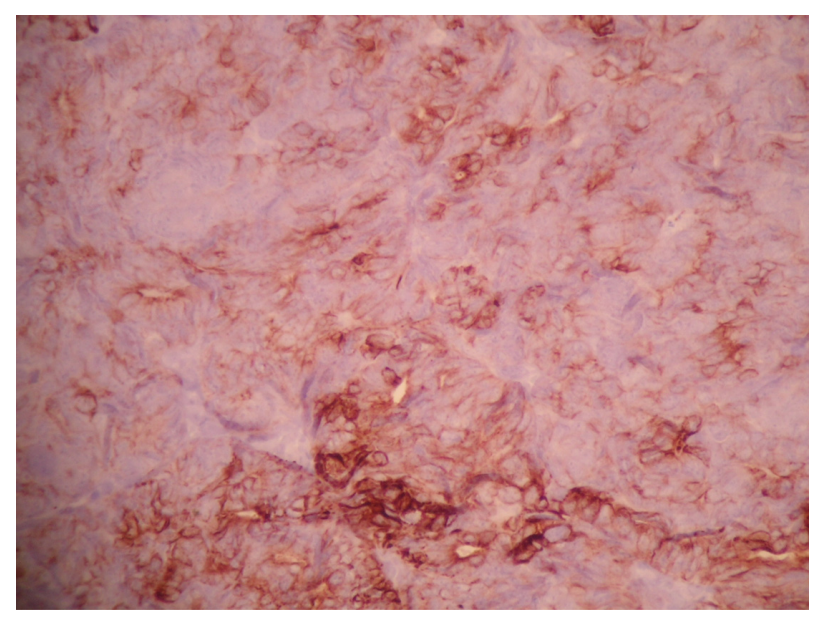

Figure 2 Immunohistochemical stain $(20 \times)$ showing tumor cells strongly positive for CK7. 
the umbilicus. Metastatic malignancy should be among the differential diagnosis of umbilical hernia. It is important to remember that fine needle aspiration biopsy, which has a high diagnostic yield, ${ }^{4,13}$ should be performed in the evaluation of any suspicious umbilical mass prior to operative intervention. With appropriate surgery, adjuvant therapy, and timely follow-up, average survival rates will be improved. ${ }^{1,4,9}$

\section{Conclusion}

Umbilical metastasis (Sister Mary Joseph's Nodule) is well known to be a late stage of malignancy and is associated with a poor prognosis. Umbilical metastasis should be among the differential diagnosis of umbilical hernia.

\section{Conflicts of interests}

The authors declared no conflicts of interests

\section{References}

1. Gabriele R, Conte M, Egidi F, Borghese M. Umbilical metastases: current viewpoint. World J Surg Oncol. 2005;3(1):13.

2. Kolwijck E, Kruitwagen RF, Massuger LF. Sister Mary Joseph nodule as a first and only sign of extraovarian carcinoma: a case report and review of the literature. Arch Pathol Lab Med. 2008;132(12):1943-1945.
3. Fill S, Taran A, Schulz HU, et al. Sister Mary Joseph's nodule as the first sign of pregnancy-associated gastric cancer: a case report. World $J$ Gastroenterol. 2008;14(6):951-953.

4. Renner R, Sticherling M. Sister Mary Joseph's nodule as a metastasis of gallbladder carcinoma. Int J Dermatol. 2007;46(5):505-507.

5. Panaro F, Andorno E, Di DS, et al. Sister Joseph's nodule in a liver transplant recipient: Case report and mini-review of literature. World J Surg Oncol. 2005;3(1):4.

6. Saito H, Shimokata K, Yamada Y, Nomura F, Yamori S. Umbilical metastasis from small cell carcinoma of the lung. Chest. 1992;101(1): 288-289.

7. Yendluri V, Centeno B, Springett GM. Pancreatic cancer presenting as a Sister Mary Joseph's nodule: case report and update of the literature. Pancreas. 2007;34(1):161-164.

8. Kurt S, Camuzcuoglu H, Camuzcuoglu A, Dicle N, Tinar S. Umbilical metastasis of serous component as a first sign of mixed type epithelial ovarian cancer. Eur J Gynaecol Oncol. 2009;30(4):455-457.

9. Galvan VG. Sister Mary Joseph's nodule. Ann Intern Med. 1998; 128(5):410.

10. Larentzakis A, Theodorou D, Fili K, et al. Sister Mary Joseph's nodule: Three case reports. Cases J. 2008;1(1):182.

11. Piura B, Meirovitz M, Bayme M, Shaco-Levy R. Sister Mary Joseph's nodule originating from endometrial carcinoma incidentally detected during surgery for an umbilical hernia: a case report. Arch Gynecol Obstet. 2006;274(6):385-388.

12. Coll DM, Meyer JM, Mader M, Smith RC. Imaging appearances of Sister Mary Joseph nodule. Br J Radiol. 1999;72(864):1230-1233.

13. Edoute Y, Malberger E, Kuten A. Umbilical metastasis diagnosed by fine needle aspiration. J Surg Oncol. 1990;45(1):56-58.
Pathology and Laboratory Medicine International

\section{Publish your work in this journal}

Pathology and Laboratory Medicine International is a peer-reviewed open access journal focusing on innovative basic research and translational research related to pathology or human disease. The journal includes original research, updates, case reports, reviews and commentaries on current controversies. The Academic Sponsor

\section{Dovepress}

of this journal is the Chinese American Pathology Association (CAPA). The manuscript management system is completely online and includes a very quick and fair peer-review system. Visit http://www.dovepress.com/testimonials.php to read real quotes from published authors.

Submit your manuscript here: http://www.dovepress.com/pathology-and-laboratory-medicine-international-journal 